\title{
An Exploratory Look at a MENA Leadership Yardstick
}

\author{
Caroline Akhras \\ Ph.D., Associate Professor, Notre Dame University,Lebanon, cakhras@ndu.edu.lb
}

\begin{abstract}
It is held that contemporary Western organizations would neither exist nor develop without leaders who efficiently and effectively manage. Researchers assert that in modern business enterprises, leadership requires the skill of working with and through people and other organizational resources to accomplish organizational goals. In addition, many business leadership studies posit that a key skill is that unique ability to work with the additionally challenging behavior of Millennials and Generation $\mathrm{Z}$ geared 24/7 towards accelerated development. Nonetheless, Drucker (2003) looking at modern organizations from a much broader perspective asserted that effective management in the post-industrial arena is probably the main resource of the developed world and the most needed resource in the developing world. This research paper explores perceptions of a leadership yardstick in small and medium-sized enterprises (SME) in the Middle East and North Africa (MENA). Ninety three participants drawn from different departments in business organizations were randomly selected as a sample. Two research questions were posed: (1) In your opinion, are business leaders operationally efficient in reaching goals in the SME where you work? (2) In your opinion, are business leaders effective in reaching goals in the SME where you work? The results found that Millennial and Generation $Z$ business leadership in the MENA had a novel moral compass that networked, coordinated, cooperated and united employees into a communal context. Additional research is recommended to further explore and understand the modern MENA business leadership yardstick as it is the first worldwide horizontal generation that seems to be socially accountable.
\end{abstract}

KEY WORDS: Business Context, Leadership Yardstick, Millennials, Generation Z, Modern Morality, Active Investment, SME

\section{Introduction}

The modern world is challenging on all accounts. An economy recovering from recession, a bold boisterous, at times, extreme and rampant political climate, an openly mixed diversified demography, a geometric advancement of technological innovation, a colossal growth of wealth for a few, and a global entrepreneurial spree of success juxtaposed with ravaging war, terrorism, impoverishment, and massacres. Within this contextual whirlpool, cultures shift, society evolves, people adapt, and businesses align as leadership does. This research paper explores perceptions of a leadership yardstick by generational cohorts in small and medium-sized enterprises in the development sector of an emerging country in the Middle East and North Africa. This new generational cohort of leadership, Millennials and Generation Z, may be seen as a driving force with a new edge on leadership given their modern morality and horizontal integration.

The Lebanese youth belong to a rich diversified culture, but its people are Westernized even though they are from the Middle East and North Africa (Deresky 2017; Robbins, Coulter, Sidani, and Jamali 2015). Despite the stark confessional divisions of its nation and the markedly changed general and operating environment, Lebanon, a Mediterranean democracy, has a free market trade tradition and a robust history of private commercial activity. At present, Lebanon's economic freedom score is the $154^{\text {th }}$ freest in the 2019 index; moreover, the economy's overall size has declined. This mirrors declines in judicial effectiveness, trade freedom, and investment freedom which outweighs the modest improvement in labor freedom. In addition, the political deadlock in 2018 meant that policy implementation and legislation on improving tax and the regulatory environment was mired as was attracting foreign investment and private-public partnerships (Heritage Foundation 2019; The World Bank IBRD-IDA 2019).

Given that the study explores business leadership benchmarks, the first part of the research paper reviews literature on small and medium sized enterprises and leadership, focusing on the leader's relationship among followers to attain organizational success. The second part of the literature reviews workplace generational cohort, Millennials and Generation Z, in terms of the changing nature of work, social media, and culture in the fourth industrial revolution. Following the 
literature review, the research methodology adopted is described in terms of the purpose of the study, research questions, participants, procedures, research design, analysis of data and rubrics. Then in the fourth section, the research methodology discusses the results whereas the fifth section summarizes the research findings drawn from the study in the conclusion, clarifies the implications and limitations of the research, and proposes recommendations and future research.

\section{Literature Review}

Workplace paradigms have shifted, and benchmarks that clarify standards are continuously revamped. Nonetheless, within the business context, it is held that leaders build commitment, establish order and generate success (Robbins and Judge 2018; Dessler 2018). In what follows, literature is reviewed on small and medium sized enterprises, business leadership, the leadership yardstick, and generational cohorts.

All countries have a large amount of businesses as well as nongovernmental organizations many of which are SME. Modern SMEs are faced with economic, political, legal, cultural, social, technological, geographic, and infrastructure factors along with global competition, price pressure, customer demands, product customization, and supplier responsiveness. Intensified price pressure is met by continuous gains in productivity, operational efficiency, and flexible customerresponsiveness. Many of these business enterprises rapidly emerge and prosper; others incrementally gain a dominant place in the market; some take over the place of other older businesses (European Commission 2019). Astute managers of SMEs often find opportunities to provide complementary resources or capabilities that are translated into an innovative product offerings or a worldwide licensing agreement. In effect, many of these SMEs attain targeted organizational goals. Studies assert that such stellar performance in the marketplace is derived from business leadership, individuals who have generated and implemented strategy using operational efficiency and effective management targeting SME objectives competitively (Ferrell, Hirt, and Ferrell 2018, 244-246).

It is held that the greatest competitive advantage in business in the twenty-first century is its leadership: leaders who have risen, proven their professional competence, and broadened the strategic and cross-cultural horizon. Studies hold that business leaders understand that increased competition requires openness to new experience, rethinking older culturally conditioned modes of leadership and adopting a new business mind-set which means achieving organization's objective while achieving those of every employee--adopting a more flexible approach to leading, potentially a soft skill (Rao 2014; Friedman and Mandelbaum 2011).

Furthermore, studies show that SMEs are led by those who work with and through people as well as other organizational resources to accomplish organizational goals. Leaders use skills and intelligence to generate products and services that meet the needs of society such as wealth, knowledge, food, clean water, medicine, shelter, and education. Many do so by looking outward: Because they are open to new experience, they embed a learning culture and thus create a learning organization in which the value of learning, innovation, experimentation, flexibility, and initiative are embedded within the organizational culture (Daft 2017; Oehler, Stomski, and Kustra-Olszewska 2014; Muller, Geraldi, and Turner 2012).

Such organizations rapidly use acquired knowledge from a variety of external sources as publication on results of applied research books, articles describing practitioner experiences, observation of best practices used elsewhere, purchasing the right to use specific knowledge from another institution, advice from consultants, joint ventures, and strategic alliances. Moreover, the process of examining and adopting best practices used in successful organizations is sometimes called benchmarks. Yardsticks, a genre of benchmark, is a standard of comparison used to judge the quality, value or success seen as beneficial in gaining a distinctive competitive advantage, commonly adopted by entrepreneurs in the marketplace (Certo and Certo 2016; Taschner 2016).

Consequently, business studies show that many leaders thoughtfully strategize the organization's future--short-term plans, medium range plans and long-term plans, a series of interconnected activities carried out across a defined period of time. Each of the plans and activities 
is budgeted and carefully controlled, expending costly resources. Given the fierce competition in the marketplace, many times operational efficiency becomes the organizational muscle, the competitive edge, and its distinctive competence (Johnson, Whittington, Scholes, Angwin, and Regner 2018). Operational efficiency shows the capacity of the organization to deliver products or services to the end customer in the sought for condition or better. Moreover, operational efficiency is often perceived as how resources flow within the enterprises using a systems approach of inputs, transformation, and outputs. It is many times seen as how well enterprises use their input resources as land, knowledge, time, technology, human capital, capital, loan, and subsidies to produce output often calculated in terms of customer satisfaction, employee development, loan portfolio and/or profit. Moreover, many management researchers hold that operational efficiency is inextricably related to managerial effectiveness (Scarborough and Cornwall 2018; Yukl 2012).

In addition, business scholars hold that many leaders actively invest in four different managerial practices as they strategize modern enterprises: communication, traditional management, human resource management, and networking. Proactively, in communication, leaders engage in exchanging routine information, processing paperwork, conveying results of meetings, writing reports, developing financial reports, sharing information on the phone, and most importantly orally communicating face-to-face; second of all, in the traditional management, leaders employ four fundamental functions that are the foundation and framework of every small and medium sized enterprises (Ferrel, Hirt, and Ferrell 2018). In traditional management, leaders plan, organize, lead, and control: leaders define objectives, formulate and implement plans; then, leaders decide how organizational resources are invested-who does what, where and how as leaders instruct, guide, support, mentor, handle day-to-day operational crises, monitor performance data, and apply preventive maintenance; third of all, in human resource management, leaders motivate/reinforce, listen to suggestions and convey appreciation, allocate formal rewards, invest in group support, resolve conflict, appeal to higher authority as they train and develop followers; lastly, leaders network, socialize, interact with outsiders, and engage in politicking. In these managerial practices and managerial functions, leaders have shared meaningful time in making decisions with valued constituencies in the business context (Robbins, Coulter, and DeCenzo 2017; Feser, Mayol, and Srinivasaan 2014).

It has been posited that decision making is one of the most important processes undertaken by leaders (Scandura 2016, 137-166; Yukl 2012). Much of what is done throughout the working day in terms of leadership involves decision making and implementation. Many leaders involve others in this important decision making process since it is seen as a political process in democratic countries whereby citizens have the right to influence a decision that will affect them. Many times, it is mandatory based on a hierarchical issue whereby decisions can only be approved and implemented when followers are involved in participative management (Javidan and Teagarden 2010). Furthermore, despite the trend towards competition and assertiveness in many industries, many organizations stress teamwork and compromise--horizontal collaboration and self-directed teamsapproaches which are said to harness the best of future workers who are said to be technologically adept, multi-tasking, simultaneously extroverted with colleagues on social media, performing conscientiously in virtual offices $24 / 7$, while reflecting professional decorum in face-to-face physical workplaces (Prensky 2016; Kowske, Rasch, and Wiley 2010).

It is held that the next generation firm is mainly made up of Millennials born 1980-1994 and Generation Z born 1995-2010 who have not only been strongly influenced by the economic, political, and technological upheaval in which they have grown up in but also by the social and cultural shift in society (The World Bank IBRD-IDA 2019; Heritage Organization 2019; Friedman 2008). Research holds that both of these generational cohorts share the ability to adapt to the global world and to its wireless internet ubiquity of total continuous connectivity. These cohorts are highly engaged in a virtual peer ecosystem, a broad based social media, and its aftermath (Bencsik, Juhasz, and Horvath-Csikos 2016, 90; Kowske, Rasch, and Wiley 2010).

In addition, research holds that Millennials are seen as idealistic, overly entitled, carving a lofty career whereas Generation Z are said to be a different "beast," pragmatic, diverse, cautious, 
hardworking, more respectful and mindful of the future having witnessed two recessions and 9/11 (Iorgulescu, 2016; Mert 2015; Twenge 2014; Deal, Altman, and Rogelberg 2010). Research studies also posit that Generation $\mathrm{Z}$ are highly charged; imploding, uploading, re-thinking, re-crafting, and leveraging new practices in the modern workplace (Chillakuri and Mahanandia 2018; Cameron and Pagnattaro 2017, 317).

Given this overview, is it feasible to hold that a leadership yardstick constituted by operational efficiency and managerial effectiveness may be held as a benchmark to lead a challenging generational workforce?

\section{Methodology}

Using descriptive research methodology, the case study explored perceptions on a leadership yardstick in different SMEs in the local context of one emerging country in the MENA. In what follows, the methodology section covers the purpose of the study, research questions, participants, the survey, the procedures used in the study, the research design, the analysis of data used and, lastly, rubrics as descriptive scorings, schemata, are defined by criteria, indicators and scales to assist in the analysis of participant' perceptions.

The purpose of the study was two-fold: (1) to explore whether local business leaders are perceived to be operationally efficient; (2) to explore whether local business leaders are perceived to be effective. In line with that, two research questions were generated in order to explore perceptions of a leadership yardstick in the local context:

- Research Question One: In your opinion, were business leaders operationally efficient, in the SME where you work?

- Research Question Two: In your opinion, were business leaders effective in the SME where you work?

The study was conducted on a convenience sample in which the participants were diversified, composed of 47 males and 46 females attending university courses and employed in the business industry. The age range was between 22-38 years. As employees in the business industry and as graduate and undergraduate courses in different Schools of Business in more than one campus in different districts across the country, they were at a point where they had both pragmatic and theoretical knowledge of the concepts being assessed. The survey they filled out included an assurance of confidentiality related to information shared and a request that the information on participants' perception of the leadership yardstick was an honest and pragmatic appraisal. Given their understanding of the external context, and assured of confidentiality, the participants were asked to be open, honest, and explicit. They were given 20 minutes to answer the survey which included three parts. Preliminary questions covered general demographics and five questions related to the content area of which three open-ended question required reflection and discussion and two asked the participants to rank variables on the Likert scale from 1-5 where 1 had the weakest value and 5 the highest.

Moreover, the research design applied was a qualitative study exploring perceptions of a leadership yardstick in terms of two measures, operational efficiency and managerial effectiveness, in a localized context, SMEs in the MENA. Descriptive statistics were used to explore the data collected on participants' perception of a leadership yardstick. As a result, five variables were explored: a leadership yardstick, efficient leadership, effective leadership, Millennial leadership, and Generation Z leadership.

- Leadership Yardstick: The participants were asked to share their opinion on two pragmatic variables, operationally efficient leadership and managerially effective leadership which form the benchmark, the leadership yardstick.

- Efficient Leadership: The participants were asked to share their opinion on how operationally efficient their leader was in one inclusive efficiency index based on empirical evidence. 
- Effective Leadership: The participants were asked to share their opinion on how effective their leader was in one inclusive effectiveness index based on empirical evidence.

- Millennial Leadership: The participants were asked to share their thoughts on whether foreign perceptions of Millennial leadership were locally applicable

- Generation Z Leadership: The participants were asked to share their thoughts on whether foreign perceptions of Generation Z leadership were locally applicable.

Furthermore, two rubrics were developed to assess the leadership yardstick: both rubrics reflected criteria, indicators, and scale.

- Operational Efficiency Rubric: The rubric was made up of two measures. First, the leader's operational efficiency was rated on the Likert scale from 1-5 where 1 was the lowest score and 5 was the highest. The score represented the optimal use of organizational resources that included knowledge, information technology, capital, raw material, time, land, and human resources. Second, the leader's operational efficiency was described based on empirical evidence drawn from the workplace.

- Managerial Effectiveness Rubric: The rubric was made up of two measures. First, the leader's managerial effectiveness was rated on the Likert scale from 1-5 where 1 was the lowest score and 5 was the highest score. The score represented the optimal use of the four managerial functions of planning, organizing, influencing, and controlling to attain SME objectives. Second, managerial effectiveness was described based on empirical evidence drawn from the workplace.

In short, having reviewed the relevant literature related to the leadership yardstick and explained the case study methodology undertaken, in what follows, the results are discussed.

\section{Results and Discussion}

The paradigm seems to have shifted. What Used to be Us (Friedman and Mendlebaum 2011) has changed; what was Hot, Flat, and Crowded (Friedman 2008) is now socially accountable and horizontally integrated. Exploring the MENA yardstick opened a broader conception on what is really involved in leading SMEs in emerging countries; Now Managing in the Next Society (Drucker 2003) seems to be the most sought for resource only when it embraces the first international horizontal generation's modern morality.

The findings drawn from the study ascertain that local leaders were perceived to be operationally efficient (3.48 on a 5 point Likert scale) and managerially effective (3.74 on a 5 point Likert scale). Participants, who were mainly Generation Z (95\%) and were performing the "rites of passage" of jobentry lower-level managerial jobs at the bottom of the local SMEs, perceived local business leadership, who were Millennial and Generation Z, as good or above average. The results of Research Question One, "In your opinion, were business leaders operationally efficient in the SME where you work?" showed that MENA local leaders were seen as operationally efficient (3.48 on a 5 point Likert scale) and is reflected in the randomly selected participants' direct quotes on local leadership.

1. "Yes, most of the leaders in Lebanon are quite efficient. They do things in the right way. In my personal experience, I could see the efficiency level of leaders in a particular company when I worked as an intern."

2. "No managers bend the rule; waste resources; don't spend their time wisely."

3. "Yes, managers in most cases are efficient. For example, I once gave feedback at a restaurant. The restaurant manager used my feedback/this resource to contact me and immediately resolved the issue."

4. "No, not really because they don't always take into consideration expert opinions to undertake a solution that best serves their interests; For example, waste management: Environment engineers are not taken into consideration." 
5. "Yes. Even though business leaders have limited resources, are able to do things right. Best use of most of resources, difficult with political situation."

The results of Research Question Two, "In your opinion, were business leaders effective, reaching targeted objectives, in the SME where you work?" showed that MENA local leaders were perceived as being effective (3.74 on a 5 point Likert scale) and is reflected in the randomly selected participants' direct quotes found below.

1. "Leaders aim to be effective rather than efficient since their primary goal could be to reach the highest level of success possible. They wouldn't mind spending more money to reach their objective. An example could be a small bakery shop spreading flyers across the neighbourhood to inform people of their products."

2. "As business leader's effectiveness, I think Lebanese firms are good in doing the right things because they like to profit. For example, services provide for customers in Lebanon is one of the best, like waiters, salespeople, insurance companies. They are quick and always smiling. Follow procedure."

3. "Yes and No. The mind set is to just get the job done: follow orders. Then they receive fast bonuses and upgrades."

4. "Yes. When a manager at a restaurant apologizes and serves a free desert because the service was late. I also know many people who own small businesses that are successful. They accomplish their goals since they are effective and do lots of innovation from time to time."

5. "Yes because they mostly end up reaching the goal in spite of all the difficulties in Lebanon but waste lots of resources. For example, the Matn highway, the goal was to build this highway to make it easier and faster to reach the mountain. The goal was reached but resources and design are not that efficient; there is traffic."

As shown in the examples above on Research Question One and Research Question Two, it was found that in traditional centralized or contemporary decentralized SMEs in Lebanon, the yardstick was applicable. It can be seen that the participants voiced their thoughts and provided pragmatic applications on whether their leader's performance was operationally efficient and effective; moreover, the observations and explorations showed linear assessments that were specific, measurable, attainable, relevant, and timely.

It seems that leaders in tall family-based SMEs exercised strict control asserting that followers should be told what to do and how to do it. Most of these leaders were Millennials who, as they grew up were repeatedly told, "Believe in yourself; you are special" (Twenge and Campbell 2010; Myers and Sadaghiani 2010). Inside the SME, it seems Millennial leaders maintained rigid hierarchies and micro-managed the managerial functions of planning, organizing, leading and controlling. Moreover, Millennials structured jobs, fixed work processes, and managed procedures. Inside most of these SMEs, bureaucratic power was not distributed; authority was hoarded, yet these traditional antiquated system were able to sustain leadership and financial mobility (Chillakuri and Mahanandia 2018; Deresky 2017; Robbins, Coulter, and DeCenzo 2017). On the other hand, inside other SMEs, participation linked authority to empowerment, follower to leader and follower to follower in a horizontal continuum of decentralized decision making where participants functioned as a community, cooperating, collaborating, and compromising.

This new generational cohort, mainly Generation Z, the iGen (Twenge 2018), impact and is impacted by operational efficiency and managerial effectiveness in the MENA and internationally as was reflected in the review on literature (Ferrell, Hirt, and Ferrell 2018; Cameron and Pagnattaro 2018; Bencsik, Juhász, and Horváth-Csikós 2016; Muller, Geraldi, and Turner 2012). It seems that in the modern workplace, cohorts engendered a communal identity. Mainly, Generation $Z$ leaders/followers had adopted multiple approaches to integrate since they were technologically adept, multi-tasking participants who were on social media, in virtual offices, and face-to-face in the workplaces what Prensky (2018) called the first international horizontal generation. 
1. "Generation $\mathrm{Z}$ leaders have characteristics of confidence; make decision that affect company; good control over their employees; monitor tasks; good way or not. Moreover Lebanese leaders are collaborative since they work with their employees as a team and inspire or encourage them to get their task done perfectly."

2. "Yes, especially restaurants employ Millennials and even more Generation Z. These leaders are similar to an American leader, open to more information. Lebanese are worldwide. Customer feedback is proving that all managers will do whatever it takes to satisfy customers. Leaders are becoming similar everywhere."

3. "I am a floor manager. I am not egocentric; I am open to suggestions and innovations"

4. "Millennial. Yes born in a period where they should be more responsible So they had to be selfconfident and self-absorbed, reach goals even where it was harder to do it, be best persons to do the job, use knowledge, use technology in their work."

5. "I met a Millennial gym owner who is a female body builder; expanding her business; opening new gyms; working with others not self-absorbed. In fact she acts like a Generation Z leader. I believe she has the qualities of an American Generation $Z$ leader because she runs her business very efficient very effective working on growth; maintaining sustainability."

On the other hand, the results show that many of the generational cohorts perceived a new work environment in which the why and the how were conceptually challenging This paradigm shift unnerved them. The genre of the workplace had changed: the nature of the work shifted away from mundane jobs of stocking shelves, filing and photocopying paperwork to more complex ones of performing research, handling complicated data, and using smart technology. Leaders and followers were confronted with a growth in highly cognitive non-routine work worldwide (Gordon 2016) as is aptly posited by Kuhn, "When the transition is complete, the profession will have changed its view of the field, its methods, and its goals" (1970, 84-85). Yet the results show that notwithstanding the paradigm shift, Millennials and Generation $Z$ were engaged, reflecting soft skills (see quotes above).

The results show that apart for ascertaining the leadership benchmark, it was found that the generational cohorts had a thirst for adventure, an openness to experience, and a capacity to change, "I am open to suggestions and innovations" (see quotes above). Notwithstanding that Generation Z's highly sought for entry-level position in which as a novice, the participants were focused on learning professional skills, upgrading and proving their credentials; notwithstanding that shifts in work and entry level expectations in an economy struggling with recession were factors the participants were highly aware of and reacted to (Toth-Kaszas 2018); and notwithstanding the fact that Generation $\mathrm{Z}$ in general was ranked at the very bottom of a very tall paternal nepotistic MENA hierarchy that traditionally established a stable secure career as that of the Millennials in the increasingly sophisticated value chains in the MENA (Deresky 2017; Robbins, Coulter, Sidani, and Jamali 2015), it seems that Generation $Z$ was perceived as socially and mutually accountable.

To sum up, what can be drawn from the results is that the yardstick reflected skilled leaders who successfully steered businesses in turbulent competitive times guiding and supporting the entitled Millennials and the less rebellious other-centered Generation Z workforce.

\section{Conclusion}

In conclusion, the paper's main contribution to the field of study lies in ascertaining the value of the leadership yardstick and in uncovering new socially accountable ubiquitous digital natives. Using descriptive research methodology, the study explored business leadership yardstick perceptions in MENA focusing on Millennials and Generation $Z$ and found that contemporary SMEs would neither exist nor develop without leaders who embrace modern morality and are operationally efficient and effective.

The future implications of the study are for those making active investment in the operating or internal environment: Within the task environment, stakeholders might take advantage of the pragmatic and theoretical information on leading the new workforce. Given that the study provided ample information on the operational efficiency and effectiveness of Millennial and Generation leaders/followers, companies planning to invest in the MENA might apply it to harness the 
narcissistic Millennial and the tolerant social-reformist Generation $\mathrm{Z}$ and build a healthy vibrant community in the service or industrial sector. Moreover, from this exploratory study, local leaders can take steps inside their business to bridge the mind-set and build closer, intimate, wired networks, bridges, liaisons, and $24 / 7$ connectivity to foster mentoring relationship of new leaderfollower and new follower-follower.

With that in mind, it should be noted that the study met a few limitations. The research design was descriptive with the purpose to explore perceptions using a leadership yardstick as an index of operationally efficiency and managerial effectiveness met with restricted access to participants. Unfortunately, administrators in local organizations were reluctant to provide open access to information and controlled access to its students and employees. Furthermore, given that MENA culture in general is a closed, contained, inclusive, and private and the research was exploratory, access to a forthright reflection of leadership may have been curtailed. As such, using a convenience sample of 93 helped minimize the secrecy and control dilemma.

Given that the results of this exploratory research were indicative of perceptions of leadership yardstick drawn from Millennials and Generation Z, young business people in SMEs in the MENA, the results point to the need for additional research to be undertaken to broaden the knowledge platform for leaders to optimize their yardstick. In line with that, potential areas of future research lie in five areas: (1) developing emotional intelligence to better understand follower-leader connectivity, (2) enhancing follower people skills as MENA generational cohorts are apprehensive about their interpersonal relationship especially those that are face-to-face, (3) providing a better work/life balance as time devoted to work/followership and valued personal time, (4) incorporating and regularly upgrading emerging social and digital tools for the always-connected Generation Me and iGen (Twenge 2018; Twenge 2014) and finally, (5) ensuring multiple pathways for career advancement for generational cohorts.

In conclusion, the focal area of leadership research as always is the heartbeat of business organizations, its human capital, ever diversified, ever challenged, and ever troubled.

\section{References}

Bencsik, A., Juhász, T., and Horváth-Csikós, G. 2016. "Y and Z Generations at Workplaces." Journal of Competitiveness 6(3): 90-106.

Cameron, E. A., and Pagnattaro, M. A. 2017. "Beyond Millennials: Engaging Generation Z in Business Law Classes." Journal of Legal Studies Education 34(2): 317-324. https://doi.org/10.1111/jlse.12064

Certo, S. C. and Certo, S. T. 2016. Modern Management: Concepts and Skills. $14^{\text {th }}$ ed. Boston: Pearson.

Chillakuri, B., and Mahanandia, R. 2018. "Generation Z Entering the Workforce: the Need for Sustainable Strategies in Maximizing their Talent." Human Resource Management International Digest 26(4): 34-38. https://doi.org/10.1108/hrmid-01-2018-0006

Daft, R. L. 2017. The Leadership Experience.7th ed. New York, USA: South-Western Cengage Learning.

Deal, J. J., Altman, D. G., and Rogelberg, S. G. 2010. "Millennials at Work: What We Know and What We Need to Do (If Anything)." Journal of Business and Psychology 25(2): 191-199. https://doi.org/10.1007/s10869-010-9177-2

Deresky, H. 2017. International Management: Managing Across Borders and Cultures (9 ${ }^{\text {th }}$ ed.). Harlow, England: Pearson.

Dessler, G. 2017. Human Resource Management. $15^{\text {th }}$ ed. Global Edition. New Jersey: Pearson.

Drucker, P. F. 2003. Managing in the Next Society. Manhattan, New York: St. Martin's Griffin.

European Commission. 2019. Entrepreneurship and Small and Medium Sized Business. https://ec.europa.eu/growth/smes_en

Ferrell, O. C., Hirt, G. and Ferrell, L. 2018. Business. $6^{\text {th }}$ ed. New York: McGraw-Hill Irwin.

Feser, C, Mayol, F, and Srinivasaan, R. 2014. "Decoding Leadership: What Really Matters?” McKinsey Quarterly 4: 89-91.

Friedman, T. 2008. Hot, Flat, and Crowded. New York: Farrar, Straus, \& Giroux.

Friedman, T. and Mandelbaum, M. 2011. That Used to Be Us. New York: Farrar, Straus, \& Giroux.

Gordon, R. 2016. The Rise and Fall of American Growth. New Jersey: Princeton University Press.

Heritage Foundation. 2019. 2019 Index of Economic Freedom. https://www.heritage.org/index/country/lebanon.

Iorgulescu, M. 2016. "Generation Z and its Perception of Work." Cross-Cultural Management Journal 18(1): 47-54.

Javidan, M. and Teagarden, M. 2010. "Making it Overseas." Harvard Business Review. Massachusetts, Boston: Harvard Books School Press. 
Johnson, G, Whittington, R., Scholes, K., Angwin, D., and Regner, P. 2018. Exploring Strategy: Texts and Cases.1 ${ }^{\text {th }}$ ed. Harrow, England: Financial Times. Prentice Hall.

Kowske, B. J., Rasch, R., and Wiley, J. 2010. "Millennials' (Lack of) Attitude Problem: An Empirical Examination of Generational Effects on Work Attitudes." Journal of Business and Psychology 25(2): 265-279. https://doi.org/10.1007/s10869-010-9171-8

Kuhn, Y. 1970. The Structure of Scientific Revolutions., University of Chicago Press: Chicago.

Mertz, J. 2015. Activate Leadership: Aspen Truths to Empower Millennial Leaders. Texas: Thin Differene

Muller, R., Geraldi, J., and Turner, J. R. 2012. "Relationships between Leadership and Success in Different Types of Project Completion." IEEEC Transactions on Engineering Management 59(1): 77-90. http://doi.org/10.1109/TEM2011.2114350.

Myers, K. K., and Sadaghiani, K. 2010. "Millennials in the Workplace: A Communication Perspective on Millennials' Organizational Relationships and Performance." Journal of Business and Psychology 25(2): 225-238. https://doi.org/10.1007/s10869-010-9172-7.

Oehler, K., Stomski, L., and Kustra-Olszewska, M. 2014. "What Makes Someone an Engaging Leader", Harvard Business Review. https://hbr.org/2014 /11/what-makes-someone-an-engaging-leader/

Prensky, M. 2016. Education to Better Their World: Unleashing the Power of $21^{\text {st }}$ Century Kids. New York: Columbia TC Press.

Prensky, M. 2018. "Real World Project: Empowerment Education.” The Global Future Education Foundation Institute. https://bit.ly//2MLKqFq

Rao, M. S. 2014. "Soft Skills for Strong Leaders: 10 Steps to Management Success." Human Resource Management International Digest 23(3). http://doi.org/10.1108/HRMID-05-2019-0069b.

Robbins, P. R., Coulter, M., and DeCenzo, D. A. 2017. Fundamentals of Management. $10^{\text {th }}$ ed. Boston: Pearson.

Robbins, S. and Judge, T. 2018. Organizational Behaviour. Boston, Massachusetts: Pearson.

Robbins, S. P., Coulter, M., Sidani, Y. and Jamali, D. 2015. Management. Arab World Edition. Essex, England: Pearson Education Limited.

Scandura, T. A. 2016. Essentials of Organizational Behavior: An Evidence-Based Approach. California, USA: SAGE Publications.

Scarborough, I. and Cornwall, J. R. 2018. .Essentials of Entrepreneurship and Small Business Managementt.9th ed. New Jersey, USA: Pearson Education.

Taschner, A. 2016. "Improving SME Logistics Performance through Benchmarking," Benchmarking: An International Journal 23(7): 1780-1797.

The World Bank IBRD-IDA. 2019. https://www.worldbank.org/en/country/Lebanon/.../economic-outlook-october2018.

Tóth-Kaszás, N. 2018. "Is a Mid-Sized Town Enough for the Generation Z? What is Needed to Keep the Young People in Their (Home) Town?" Management 13(1): 33-48. https://doi.org/10.26493/1854-4231.13.33-48

Twenge, J. M. 2014. Generation Me: Why Today's Young Americans Are More Confident, Assertive, Entitled, and More Miserable Than Ever Before. New York: Simon \& Schuster.

Twenge, J. M. 2018. iGen: Why Today's Super Connected Kids Are Growing Up Less Rebellious More Tolerant, Less Happy - and Completely Unprepared for Adulthood. New York: Simon \& Schuster.

Twenge, J. M. and Campbell, K. 2010. The Narcissism Epidemic: Living in the Age of Entitlement. New York: Free Press.

Yukl, G . A. 2012. Leadership in Organizations. $8^{\text {th }}$ ed. New Jersey, USA: Pearson. 